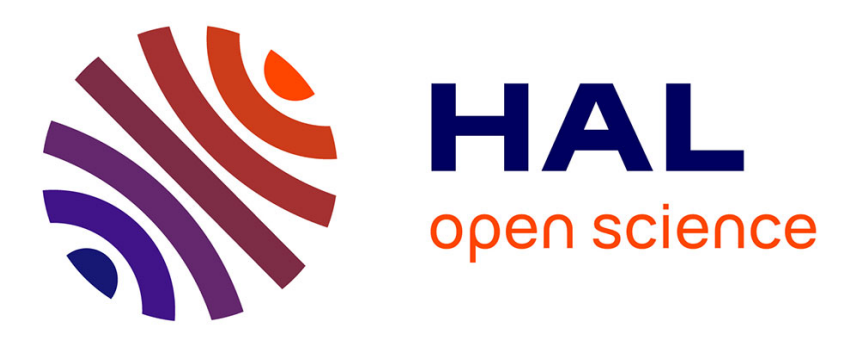

\title{
Inward Radial Mixing of Interstellar Water Ices in the Solar Protoplanetary Disk
}

Lionel G. Vacher, Yves Marrocchi, Maximilien J. Verdier-Paoletti, Johan

Villeneuve, Matthieu Gounelle

\section{- To cite this version:}

Lionel G. Vacher, Yves Marrocchi, Maximilien J. Verdier-Paoletti, Johan Villeneuve, Matthieu Gounelle. Inward Radial Mixing of Interstellar Water Ices in the Solar Protoplanetary Disk. The Astrophysical journal letters, 2016, 10.3847/2041-8205/827/1/L1 . hal-01367391

\section{HAL Id: hal-01367391 \\ https://hal.science/hal-01367391}

Submitted on 16 Sep 2016

HAL is a multi-disciplinary open access archive for the deposit and dissemination of scientific research documents, whether they are published or not. The documents may come from teaching and research institutions in France or abroad, or from public or private research centers.
L'archive ouverte pluridisciplinaire HAL, est destinée au dépôt et à la diffusion de documents scientifiques de niveau recherche, publiés ou non, émanant des établissements d'enseignement et de recherche français ou étrangers, des laboratoires publics ou privés. 


\author{
Lionel G. Vacher ${ }^{1}$, Yves Marrocchi ${ }^{1}$, Maximilien J. Verdier-Paolettit ${ }^{2}$, Johan Villeneuve ${ }^{1}$, And Matthieu Gounelle ${ }^{2,3}$ \\ ${ }^{1}$ CRPG, CNRS, Université de Lorraine, UMR 7358, Vandoeuvre-lés-Nancy, F-54501, France; lvacher@crpg.cnrs-nancy.fr \\ ${ }^{2}$ IMPMC, MNHN, UPMC, UMR CNRS 7590, 61 rue Buffon, F-75005 Paris, France \\ ${ }^{3}$ Institut Universitaire de France, Maison des Universités, 103 boulevard Saint-Michel, F-75005 Paris, France \\ Received 2016 June 3; revised 2016 June 23; accepted 2016 June 24; published 2016 August 2
}

\begin{abstract}
The very wide diversity of asteroid compositions in the main belt suggests significant material transport in the solar protoplanetary disk and hints at the presence of interstellar ices in hydrated bodies. However, only a few quantitative estimations of the contribution of interstellar ice in the inner solar system have been reported, leading to considerable uncertainty about the extent of radial inward mixing in the solar protoplanetary disk $4.56 \mathrm{Ga}$ ago. We show that the pristine CM chondrite Paris contains primary Ca-carbonates whose O-isotopic compositions require an 8\%-35\% contribution from interstellar water. The presence of interstellar water in Paris is confirmed by its bulk $\mathrm{D} / \mathrm{H}$ isotopic composition that shows significant $\mathrm{D}$ enrichment $\left(\mathrm{D} / \mathrm{H}=(167 \pm 0.2) \times 10^{-6}\right)$ relative to the mean $\mathrm{D} / \mathrm{H}$ of $\mathrm{CM}$ chondrites $\left((145 \pm 3) \times 10^{-6}\right)$ and the putative $\mathrm{D} / \mathrm{H}$ of local $\mathrm{CM}$ water $\left((82 \pm 1.5) \times 10^{-6}\right)$. These results imply that (i) efficient radial mixing of interstellar ices occurred from the outer zone of the solar protoplanetary disk inward and that (ii) chondrites accreted water ice grains from increasing heliocentric distances in the solar protoplanetary disk.
\end{abstract}

Key words: meteorites, meteors, meteoroids - minor planets, asteroids: general - protoplanetary disks

\section{INTRODUCTION}

Primitive meteorites (chondrites) were formed $4.56 \mathrm{Ga}$ years ago by the accretion of different components produced in the accretion disk: refractory inclusions, chondrules, Fe-Ni metal, and volatile-rich matrix (Marrocchi \& Libourel 2013; Scott \& Krot 2014). Submillimeter water ice grains also represented a significant proportion of the building blocks of chondrites, leading to episodes of hydrothermal alteration that have strongly modified their petrography (Brearley 2006; Marrocchi et al. 2014). Two principle sources are generally considered regarding the origin of water ices in the chondrite-accretion regions, with local water being directly condensed from the gas and interstellar water coming from the coldest part of the solar system (Lunine 2006). However, the respective proportions of local and interstellar water ices incorporated along with rock during chondrite accretion are still a matter of debate (Alexander et al. 2012).

The hydrogen isotopic composition (expressed as $\mathrm{D} / \mathrm{H}$ ratio) is a powerful tool for understanding the origin of water accreted by primitive meteorites (Duprat et al. 2010; Alexander et al. 2012; Piani et al. 2012, 2015; Jacquet \& Robert 2013). Bulk carbonaceous chondrites are enriched by a factor of 5-10 in deuterium (120-230 × 10 ${ }^{-6}$; Jacquet \& Robert 2013) relative to the initial isotopic composition of the solar system (i.e., $25 \times 10^{-6}$; Geiss \& Gloeckler 2003). The $\mathrm{D} / \mathrm{H}$ of comets is generally higher by a factor $2-3$ relative to chondritic values with $\mathrm{D} / \mathrm{H}$ values ranging from $(161 \pm 24)$ to $(530 \pm 70) \times 10^{-6}$ (Altwegg et al. 2015; Marty et al. 2016) The distribution of the $\mathrm{D} / \mathrm{H}$ of whole rock carbonaceous meteorites is asymmetric with a mean isotopic composition of $(149 \pm 3) \times 10^{-6}$ and a significant tail toward high $\mathrm{D} / \mathrm{H}$ ratios (Robert 2006; Jacquet \& Robert 2013). Considering only hydrated $\mathrm{CM}$ chondrites, bulk $\mathrm{D} / \mathrm{H}$ ratios present a significant $\mathrm{D}$ enrichment (Figure 1; mean $\left.\mathrm{D} / \mathrm{H}=(145 \pm 3) \times 10^{-6}\right)$ relative to the putative local $\mathrm{CM}$ water $(\mathrm{D} / \mathrm{H}=$ $\left.(83 \pm 1.5) \times 10^{-6}\right)$ determined from the correlation observed in $\mathrm{CM}$ chondrites between $\mathrm{D} / \mathrm{H}$ and $\mathrm{C} / \mathrm{H}$ ratios (Alexander et al. 2012). In addition, hydrated interplanetary dust particles show (i) mineralogical similarities with $\mathrm{CM}$ chondrites and (ii) $\mathrm{D} / \mathrm{H}$ isotopic compositions close to CMs, but with a significant tail extending toward cometary values (Bradley et al. 2007). Taken together, such features suggest that carbonaceous chondrites could have accreted variable contributions of water ices formed at different heliocentric distances (Jacquet \& Robert 2013).

Oxygen isotopic compositions of aqueously formed minerals in hydrated chondrites can be also used to better estimate the contribution of interstellar water ices in CM chondrites (Sakamoto et al. 2007; Fujiya et al. 2015). Oxygen isotopic compositions are expressed in delta units $(\%$ ) relative to the Standard Mean Ocean Water (SMOW; $\delta^{17,18} \mathrm{O}=$ $\left.\left[\left({ }^{17,18} \mathrm{O} /{ }^{16} \mathrm{O}\right)_{\text {sample }} /\left({ }^{17,18} \mathrm{O} /{ }^{16} \mathrm{O}\right)_{\text {SMOW }}-1\right] \times 1000\right)$ and massindependent variations of oxygen isotopes are described by the parameter $\Delta^{17} \mathrm{O}$, defined as $\Delta^{17} \mathrm{O}=\delta^{17} \mathrm{O}-0.52 \times \delta^{18} \mathrm{O}$ (Marrocchi \& Chaussidon 2015). Outer disk water ices are expected to present significant ${ }^{17,18} \mathrm{O}$-rich enrichments $\left(\Delta^{17} \mathrm{O} \gg 0\right)$ relative to the terrestrial values due to the selfshielding of ${ }^{16} \mathrm{O}$-rich nebular CO gas by UV light (Clayton 2002; Lyons \& Young 2005; Yurimoto et al. 2008). Meteoritic carbonates represent direct snapshots of the isotopic compositions of alteration fluids and can in theory be used to decipher the origin of water in the chondrite-forming region. However, waterrich chondrites are characterized by a high degree of alteration and the dissolution of primary carbonates and subsequent precipitation of secondary carbonates have removed any record of their water ice origin (Lee et al. 2014). The recent discovery of Paris-a new CM chondrite characterized by a very low degree of alteration (Hewins et al. 2014; Marrocchi et al. 2014; Pignatelli et al. 2016) —offers a unique opportunity to (i) determine the origin of water ice grains accreted in Paris and (ii) quantitatively estimate the respective contributions of D-poor and ${ }^{16} \mathrm{O}$-rich local inner solar system water $\left(\Delta^{17} \mathrm{O} \approx 0\right.$; hereafter W-ISS, Alexander et al. 2012) and D-rich and ${ }^{17,18} \mathrm{O}$-rich interstellar water $\left(\Delta{ }^{17} \mathrm{O}=20\right.$ to $90 \%$; hereafter W-ISM; 


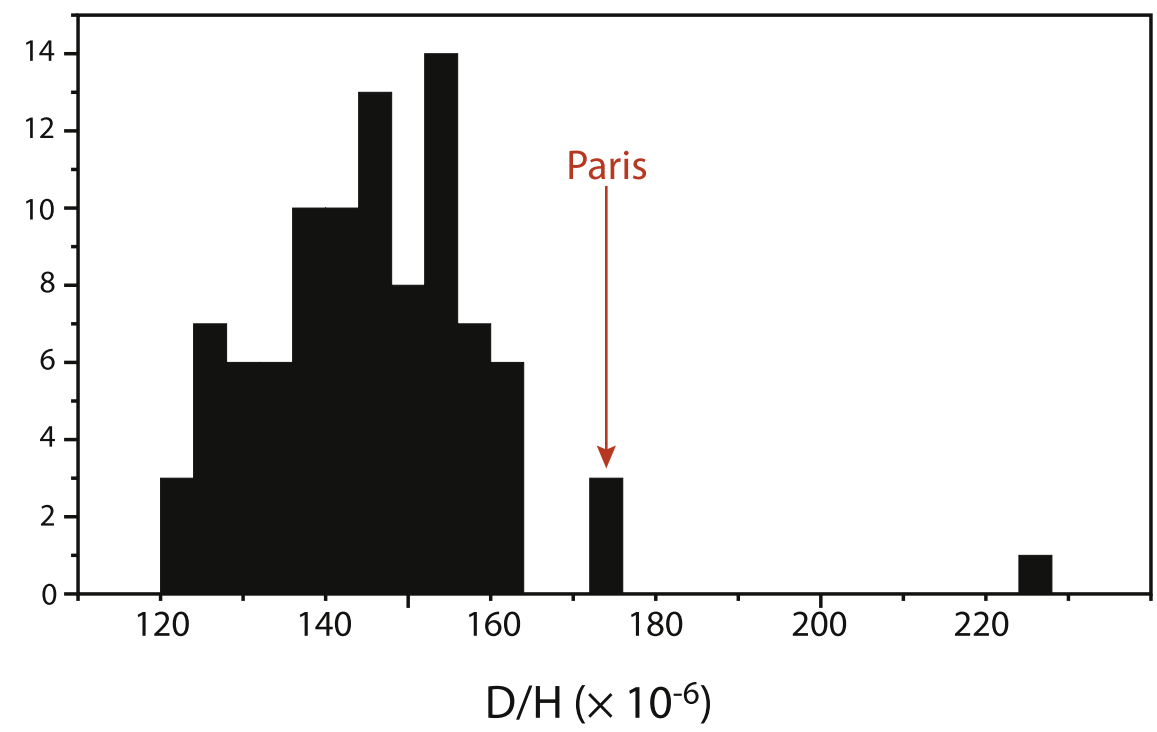

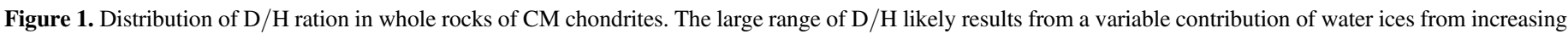

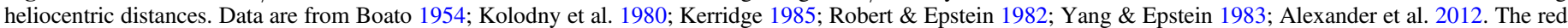
arrow corresponds to the $\mathrm{D} / \mathrm{H}$ value determined for the pristine $\mathrm{CM}$ chondrite Paris.

Sakamoto et al. 2007). In this paper, we thus report the bulk D/H ratio of the Paris chondrite and the oxygen isotopic analysis of Paris Ca-carbonates. We used the data to quantitatively estimate the proportion of interstellar ices in the inner solar system during the accretion of hydrated chondrites.

\section{MATERIAL AND METHODS}

\subsection{Water Content and Bulk D/H Isotopic Composition}

The determination of $\left[\mathrm{H}_{2} \mathrm{O}^{+}\right]$and $\mathrm{D} / \mathrm{H}$ of the Paris chondrite were performed on-line using an elemental analyzer (EA) connected to a VG Isoprime Isotope Ratio Mass Spectrometer according to the procedure developed by Lupker et al. (2012). A $10.6 \mathrm{mg}$ chip of Paris was crushed and separated in three aliquots. The samples were then pre-weighted, loaded in tin capsules, placed in a sample carousel, and degassed at $120^{\circ} \mathrm{C}$ under vacuum for $48 \mathrm{hr}$ in a degassing canister (Lupker et al. 2012; Gaudin et al. 2015). After dehydration, the automatic sampler was then connected to the EA and pumped out for 20 minutes before opening to the reduction column to suppress potential rehydration of the samples by atmospheric water (Lupker et al. 2012).

Combustion of the samples was performed at $1450^{\circ} \mathrm{C}$ on an EA glassy carbon reaction tube packed with glassy carbon chips and enclosed in a ceramic liner to reduce hydroxyls to $\mathrm{H}_{2}$. After chromatographic separation of the produced gases at $60^{\circ} \mathrm{C}, \mathrm{H}_{2}$ was introduced into the mass spectrometer and analyzed for $\mathrm{D} / \mathrm{H}$ isotopic composition. The amount of $\mathrm{H}_{2}$ produced was corrected of $\mathrm{H}^{3+}$ contribution and determined by comparison with different internal standards (e.g., muscovite, phlogopite, and fine-grained marine sediments from the Bay of Bengal). $\mathrm{D} / \mathrm{H}$ is reported as $\mathrm{dD}$ and is normalized against SMOW. The reproducibility of the method is better than $2 \%$ o $(1 \sigma)$ for $\delta \mathrm{D}$ and $0.1 \%$ for the determination of the water content.

\subsection{In Situ Oxygen-isotope Measurements}

Ca-carbonates were spotted in two sections of the Paris chondrite (\#2010-1 and \#2015-L1) using the JEOL JSM-
6510 scanning electron microscope equipped with an energy dispersive X-ray (EDX) Genesis detector at CRPG-CNRS (Nancy, France). A $3 \mathrm{nA}$ primary beam accelerated at $15 \mathrm{kV}$ was used for observations.

Oxygen isotopic compositions were measured with a CAMECA IMS 1280 HR2 at CRPG-CNRS (Nancy, France). ${ }^{16} \mathrm{O}^{-},{ }^{17} \mathrm{O}^{-}$, and ${ }^{18} \mathrm{O}^{-}$ions produced by a $\mathrm{Cs}^{+}$primary ion beam $(15 \mu \mathrm{m}, 5 \mathrm{nA})$ were measured in multi-collection mode using three Faraday cups. To remove ${ }^{16} \mathrm{OH}^{-}$interference on the ${ }^{17} \mathrm{O}^{-}$peak and to achieve maximum flatness of the ${ }^{16} \mathrm{O}^{-}$ and ${ }^{18} \mathrm{O}^{-}$peak-tops, the entrance and exit slits were adjusted on the central Faraday cup to obtain an MRP of $\approx 7000$ for ${ }^{17} \mathrm{O}^{-}$. ${ }^{16} \mathrm{O}^{-}$and ${ }^{18} \mathrm{O}^{-}$were measured on $L^{\prime} 2$ and $\mathrm{H} 1$ (slit $1, \mathrm{MRP} \approx$ 2500). Acquisition times were set to lengths that would provide counting statistics on the order of $\pm 0.2 \%$ o $(1 \sigma)$ for $\delta^{18} \mathrm{O}$ and $\delta{ }^{17} \mathrm{O}$. We measured two terrestrial standards (quartz and calcite) to define the instrument mass fractionation line. The oxygen isotopic compositions of the Paris $\mathrm{Ca}$-carbonates were normalized to that of terrestrial calcite. The typical count rates obtained on the calcite standards were $2.5 \times 10^{8} \mathrm{cps}$ for ${ }^{16} \mathrm{O}$, $1.1 \times 10^{6} \mathrm{cps}$ for ${ }^{17} \mathrm{O}$, and $5.3 \times 10^{6} \mathrm{cps}$ for ${ }^{18} \mathrm{O}$. The $2 \sigma$ errors were $\approx 0.6 \%$ ofor $\delta^{18} \mathrm{O}, \approx 0.6 \%$ ofor $\delta^{17} \mathrm{O}$, and $\approx 0.4 \%$ ofor $\Delta^{17} \mathrm{O} \quad\left(\Delta^{17} \mathrm{O}\right.$ representing the deviation from the TFL, $\left.\Delta^{17} \mathrm{O}=\delta^{17} \mathrm{O}-0.52 \times \delta^{18} \mathrm{O}\right)$.

\section{RESULTS}

The three aliquots of Paris show reproducible water content $\left(\left[\mathrm{H}_{2} \mathrm{O}^{+}\right]=4.78 \mathrm{wt} \% \pm 0.03\right)$ and hydrogen isotopic composition (Figure $\left.1 ; \mathrm{D} / \mathrm{H}=(167 \pm 0.2) \times 10^{-6}\right)$. These results are consistent with previous measurements reported for CM chondrites (Robert \& Epstein 1982; Kerridge 1985; Robert 2006; Alexander et al. 2012).

The two sections of Paris present heterogeneous alteration degrees characterized by significant differences in abundance of Fe-Ni metal beads (Figure 2(a)). Thirty-five Ca-carbonate grains were selected in the fresh areas of Paris sections (Figures 2(b) and (c)) for oxygen isotopic analysis. The O-isotopic compositions of Paris carbonates vary widely, from $24.2 \%$ to $40.8 \%$ in $\delta^{18} \mathrm{O}$ and $11.6 \%$ o to $23.8 \%$ in $\delta^{17} \mathrm{O}$ and 

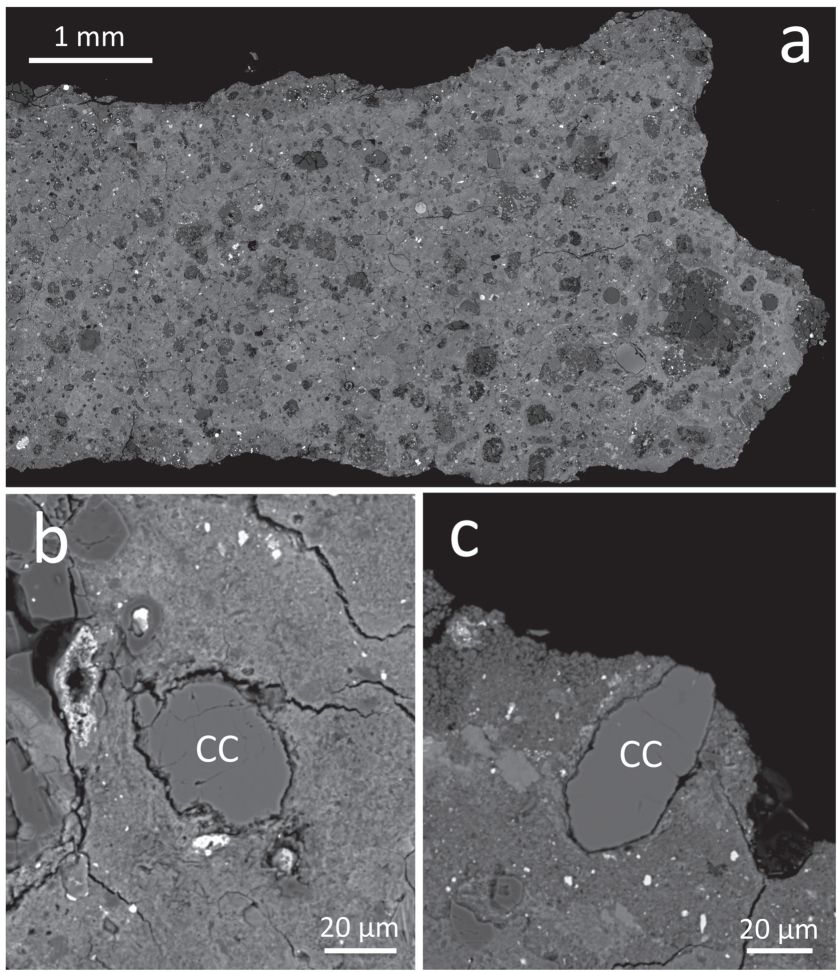

Figure 2. (a) Back-scattered electron image of a fresh metal-rich zone in one section of Paris chondrite (\#2015-L1). (b) and (c) Back-scattered images of two $\mathrm{Ca}$-carbonates dispersed through the fresh metal-rich matrix.

reveal the existence of two distinct populations of carbonates (Figure 3(a); Table 1). When combined with the literature data from other CM chondrites (Benedix et al. 2003; Tyra et al. 2012, 2016; Lee et al. 2013; Horstmann et al. 2014), the carbonate O-isotopic compositions define two statistically different trends (Figure 3(b)). The ISS trend is characterized by large isotopic variations, with $\Delta^{17} \mathrm{O}<0$ and a slope of 0.65 in a $\delta^{17} \mathrm{O}-\delta^{18} \mathrm{O}$ diagram (Figure $3(\mathrm{~b})$ ). A secondary trend shows less isotopic variation, but has $\Delta^{17} \mathrm{O}>0$ and a steeper slope $>1$ (Figure 3(b)). The inflection point between these two trends is estimated to have $\delta^{18} \mathrm{O}=39.0 \%$ and $\delta^{17} \mathrm{O}=18.5 \%$ (Figure 3(b)). The trends observed in the $\delta^{17} \mathrm{O}-\delta^{18} \mathrm{O}$ diagram demonstrate the occurrence of two types of carbonates that recorded aqueous fluids with different origins in the solar protoplanetary disk.

\section{DISCUSSION}

The main carbonate ISS population is indistinguishable within error from the trend defined by the matrix phyllosilicates and bulk O-isotopic compositions of $\mathrm{CM}$ chondrites (slope 0.65; Figure 3(b)). This continuous trend does not follow a mass-dependent fractionation trend (Figure 3(b)), implying that the carbonate $\mathrm{O}$-isotopic compositions were not affected by terrestrial alteration (Tyra et al. 2012) and did not result from fluid circulation along a temperature gradient, which would have produced a trend with a slope of 0.52 . Instead, it implies that carbonate $\mathrm{O}$-isotopic compositions are a direct proxy for the degree of $\mathrm{O}$-isotopic equilibration between ${ }^{17,18} \mathrm{O}$-rich fluids and ${ }^{16} \mathrm{O}$-rich anhydrous minerals. In addition, the fluids from which W-ISS carbonates precipitated had near terrestrial $\Delta^{17} \mathrm{O}$ values, demonstrating that most water ices accreted by $\mathrm{CM}$ chondrites had a dominantly local origin from the inner

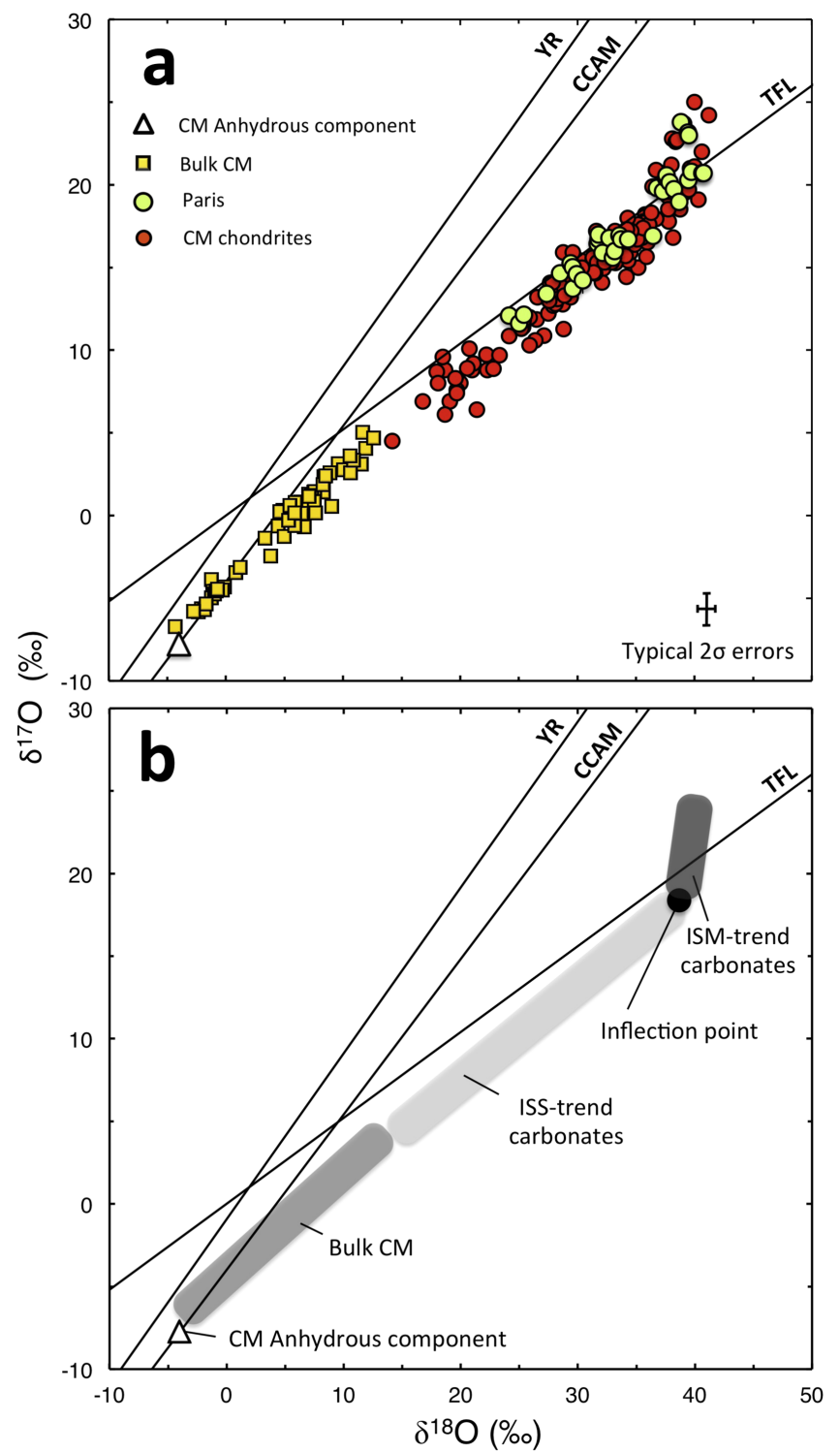

Figure 3. (a) Oxygen three-isotope plot for Ca-carbonates in Paris (this study; green squares) and other $\mathrm{CM}$ chondrites from the literature (red circles). Bulk $\mathrm{CM}$ and $\mathrm{CO}$ chondrites are also represented (yellow squares). The white triangle corresponds to the O-isotopic composition of anhydrous silicates determined from mass balance calculations (Clayton \& Mayeda 1999). Cacarbonates reveal the existence of two trends characterized by different slopes. (b) Schematic representation of the two trends defined by the O-isotopic compositions of Ca-carbonates in CM chondrites. The ISS trend is characterized by $\Delta^{17} \mathrm{O}<0$ and large $\mathrm{O}$-isotopic variability, while carbonate on the ISM trend show $\Delta^{17} \mathrm{O}>0$ and a narrow range of $\mathrm{O}$-isotopic compositions. The intersection between the two trends corresponds to the inflection point. TFL denotes the terrestrial fractionation, CCAM denotes the carbonaceous chondrite anhydrous minerals line, and YR denotes the Young and Russell line.

solar system (i.e., $\Delta^{17} \mathrm{O} \approx 0$; Alexander et al. 2012). However, the significant departure of certain carbonates from the W-ISS trend (Figures 3(a) and (b)) implies the presence of interstellar water with $\Delta^{17} \mathrm{O} \gg 0$ within $\mathrm{CM}$ chondrites (Figure 3(b)).

The contribution of interstellar water ices can be quantitatively estimated from isotopic mass balance calculations. The O-isotopic compositions of fluids from which a carbonate located at the inflection point precipitated (Figure 4(a)) were calculated at different temperatures $\left(10^{\circ} \mathrm{C}-150^{\circ} \mathrm{C}\right)$ using the equation $1000 \ln \Delta{ }^{18} \mathrm{O}=\left(2.78 \times 10^{6} \mathrm{~T}^{-2}\right)-3.39$ 
Table 1

Oxygen Isotopic Compositions of Paris Ca-carbonates

\begin{tabular}{|c|c|c|c|c|c|c|}
\hline & $\delta^{18} \mathrm{O}(\% o)$ & $2 \sigma$ & $\delta^{17} \mathrm{O}(\% o)$ & $2 \sigma$ & $\Delta^{17} \mathrm{O}(\%)$ & $2 \sigma$ \\
\hline \#1 & 24.18 & 0.23 & 12.09 & 0.47 & -0.48 & 0.38 \\
\hline$\# 2$ & 25.01 & 0.27 & 11.63 & 0.78 & -1.37 & 0.68 \\
\hline$\# 3$ & 25.45 & 0.27 & 12.14 & 0.73 & -1.09 & 0.63 \\
\hline$\# 4$ & 27.37 & 0.25 & 13.40 & 0.56 & -0.83 & 0.46 \\
\hline$\# 5$ & 28.54 & 0.63 & 14.65 & 0.59 & -0.19 & 0.46 \\
\hline$\# 6$ & 29.41 & 0.21 & 15.25 & 0.38 & -0.04 & 0.36 \\
\hline$\# 7$ & 29.59 & 0.17 & 13.72 & 0.50 & -1.66 & 0.44 \\
\hline$\# 8$ & 29.60 & 0.26 & 15.01 & 0.49 & -0.38 & 0.31 \\
\hline$\# 9$ & 29.95 & 0.24 & 14.59 & 0.55 & -0.99 & 0.46 \\
\hline$\# 10$ & 30.46 & 0.29 & 14.23 & 0.78 & -1.61 & 0.67 \\
\hline \#11 & 31.71 & 0.32 & 16.44 & 0.79 & -0.04 & 0.32 \\
\hline \#12 & 31.78 & 0.61 & 16.71 & 0.58 & 0.19 & 0.45 \\
\hline \#13 & 31.81 & 0.67 & 16.99 & 0.48 & 0.45 & 0.38 \\
\hline$\# 14$ & 32.15 & 0.17 & 15.88 & 0.51 & -0.84 & 0.44 \\
\hline$\# 15$ & 32.74 & 0.20 & 16.79 & 0.43 & -0.23 & 0.48 \\
\hline \#16 & 33.01 & 0.19 & 15.60 & 0.63 & -1.56 & 0.56 \\
\hline \#17 & 33.16 & 0.16 & 15.98 & 0.75 & -1.26 & 0.69 \\
\hline \#18 & 33.58 & 0.75 & 16.95 & 0.51 & -0.52 & 0.40 \\
\hline \#19 & 33.74 & 0.64 & 16.71 & 0.81 & -0.83 & 0.64 \\
\hline \#20 & 34.33 & 0.58 & 16.70 & 0.57 & -1.15 & 0.44 \\
\hline \#21 & 36.43 & 0.20 & 16.91 & 0.55 & -2.03 & 0.47 \\
\hline \#22 & 36.79 & 0.13 & 19.80 & 0.36 & 0.67 & 0.46 \\
\hline$\# 23$ & 37.31 & 0.13 & 19.61 & 0.51 & 0.21 & 0.38 \\
\hline$\# 24$ & 37.57 & 0.54 & 20.40 & 0.52 & 0.87 & 0.40 \\
\hline$\# 25$ & 37.60 & 0.23 & 20.57 & 0.50 & 1.01 & 0.68 \\
\hline \#26 & 37.85 & 0.19 & 20.16 & 0.37 & 0.48 & 0.46 \\
\hline$\# 27$ & 38.25 & 0.18 & 19.73 & 0.53 & -0.16 & 0.40 \\
\hline \#28 & 38.69 & 0.13 & 18.98 & 0.39 & -1.14 & 0.34 \\
\hline \#29 & 38.83 & 0.64 & 23.80 & 0.59 & 3.61 & 0.46 \\
\hline$\# 30$ & 39.41 & 0.73 & 23.15 & 0.57 & 2.65 & 0.39 \\
\hline \#31 & 39.45 & 0.60 & 20.29 & 0.45 & -0.22 & 0.35 \\
\hline \#32 & 39.51 & 0.71 & 23.00 & 0.55 & 2.46 & 0.38 \\
\hline \#33 & 39.71 & 0.16 & 20.78 & 0.43 & 0.14 & 0.41 \\
\hline \#34 & 40.66 & 0.54 & 20.70 & 0.46 & -0.45 & 0.36 \\
\hline \#35 & 40.76 & 0.14 & 20.71 & 0.67 & -0.49 & 0.61 \\
\hline
\end{tabular}

Note. $\Delta^{17} \mathrm{O}$ errors were calculated using the errors of the ${ }^{17} \mathrm{O} /{ }^{18} \mathrm{O}$ ratio.

$=\delta^{18} \mathrm{O}_{\text {carb }}-\delta^{18} \mathrm{O}_{\text {water }}($ Kim \& O'Neil 1997). In the absence of a contribution from ${ }^{17,18}$ O-rich interstellar water, the fluid compositions excepted for the inflection point define a massdependent trend that is located slightly below the TFL (defined by the colored points; Figure 4). Hence, for each temperature, we calculated the $\mathrm{O}$-isotopic composition of a fluid $\left(\delta^{17,18} \mathrm{O}_{\text {fluid }}\right)$ resulting from mixing of inner solar system water $\left(\delta^{17,18} \mathrm{O}_{\mathrm{W}-\text { ISS }}\right)$ with varying proportion of ${ }^{17,18} \mathrm{O}$-rich interstellar water (Sakamoto et al. 2007) $\left(\delta^{17,18} \mathrm{O}_{\mathrm{W}-\mathrm{ISM}}=+180 \%\right.$ ), according to the following isotopic mass balance:

$$
\delta^{17,18} \mathrm{O}_{\text {fluid }}=f \times \delta^{17,18} \mathrm{O}_{\mathrm{W} \text {-ISS }}+(1-f) \times \delta^{17,18} \mathrm{O}_{\mathrm{W} \text {-ISM }},
$$

where $f$ is the concentration of inner solar system water ices relative to the concentration of interstellar water ices. The results demonstrate that W-ISM carbonates precipitated from alteration fluids that accommodated up to $8 \%$ of ${ }^{17,18} \mathrm{O}$-rich interstellar water (Figure 4(a)).

Regardless of the temperature of carbonate precipitation, there is a significant difference in the slopes of the trends defined by the W-ISM carbonates and the slopes of the W-ISS/ W-ISM mixing lines (Figure 4(a)). This could be due to variations in the O-isotopic compositions of interstellar water.

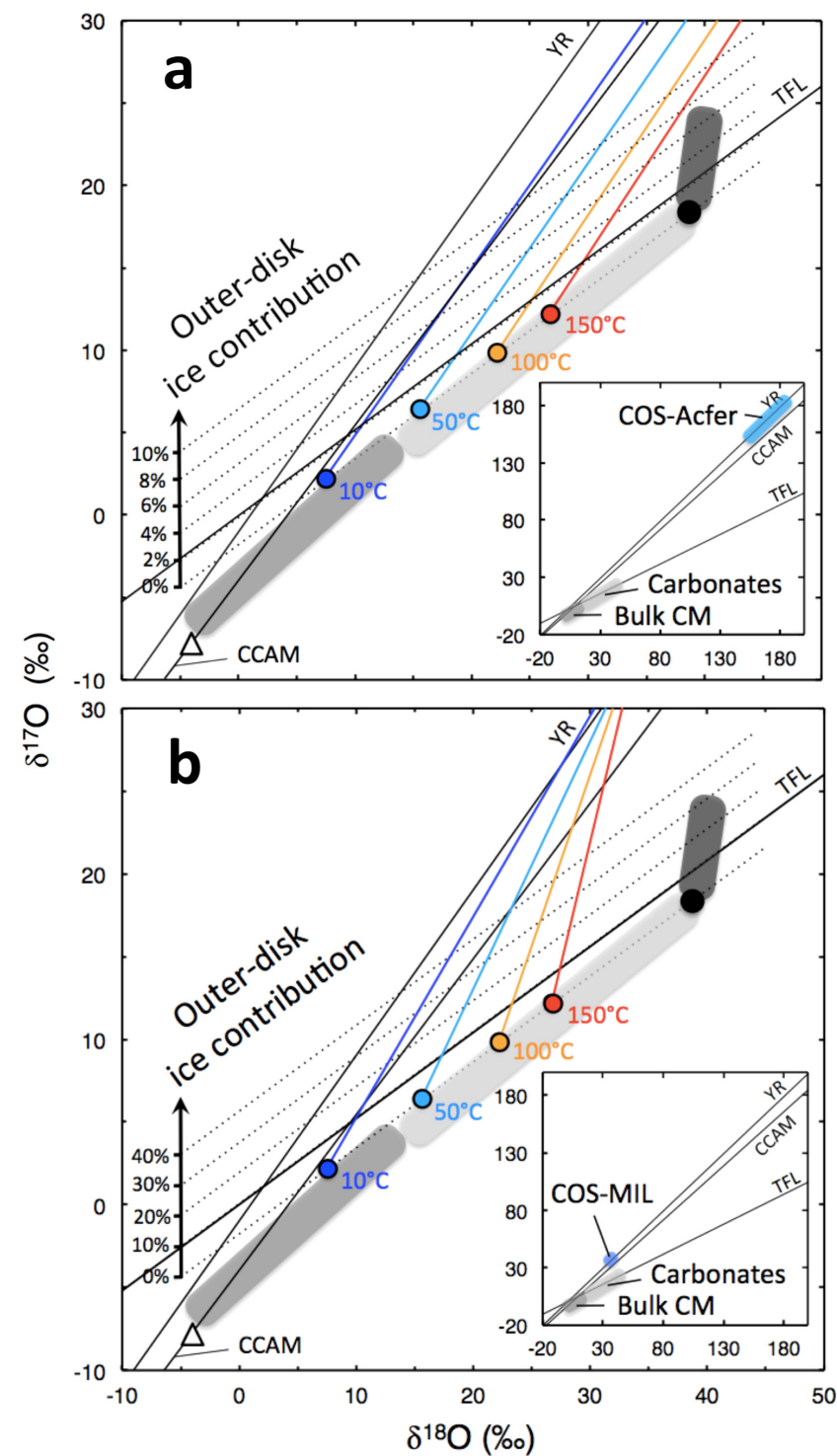

Figure 4. (a) Oxygen three-isotope plot showing the composition of the alteration fluids calculated at different temperatures $\left(10^{\circ} \mathrm{C}, 50^{\circ} \mathrm{C}, 100^{\circ} \mathrm{C}\right.$ and $150^{\circ} \mathrm{C}$ ) for a given carbonate located at the inflection point. For each temperature, the $\mathrm{O}$-isotopic compositions of alteration fluids resulting from mixing inner solar system water with varying proportions of interstellar ${ }^{17,18} \mathrm{O}$ rich water (Sakamoto et al. 2007) $\left(\delta^{17,18} \mathrm{O}=180 \%\right.$ ) are represented by colored lines starting at a given temperature. The dashed lines correspond to the percentage contributions of outer disk water ices in carbonates that lie along the ISM trend. (b) The same oxygen three-isotope plot, but recalculated to take into account the O-isotopic composition of interstellar water determined in MIL 07687 (Nittler et al. 2015) $\left(\delta^{17,18} \mathrm{O}=34 \%\right.$ o).

A recent report confirms the extreme $\delta^{17} \mathrm{O}-\delta^{18} \mathrm{O}$ values measured in the Acfer 094 chondrite (Sakamoto et al. 2007; Nittler et al. 2015), but also points out the existence of less- ${ }^{17,18} \mathrm{O}$-rich interstellar water in another chondrite (Nittler et al. 2015) (i.e., MIL 07687; $\delta^{17,18} \mathrm{O}=34 \%$; $\Delta{ }^{17} \mathrm{O}=+16 \%$ ). For the latter O-isotopic composition, the isotopic mass balance calculations reproduce the carbonate W-ISM trend (Figure 4(b)) and demonstrate the contribution of ${ }^{17,18} \mathrm{O}$-rich interstellar water ices at a level of up to $35 \%$ (Figure 4(b)).

Our results confirm the unique nature of the pristine CM chondrite Paris that kept the record of the presence of interstellar water due to its limited degree of alteration (Hewins 
et al. 2014; Marrocchi et al. 2014). At the exception of Maribo and LON 94091 (Lee et al. 2013; Horstmann et al. 2014), the O-isotopic compositions of Ca-carbonates (Figure 3(a)) of other CM chondrites suggest that they did not accrete significant amounts of interstellar water. In addition, Paris's carbonates show O-isotopic compositions that fall on both trends in the oxygen three-isotope plot (W-ISS and W-ISM; Figure 3(a) and Table 1), suggesting that the accretion of interstellar water ice grains were heterogeneous and contributed to different extents to the alteration fluids. Due to the low permeabilites of CM chondrites (Bland et al. 2009), the alteration processes are expected to be isochemical with minimal fluid flow and mainly controlled by the existence of microenvironments ( $<100 \mathrm{um}$; Bland et al. 2009). Considering Paris, these microenvironments were thus characterized by varying abundances of interstellar water relative to local water, leading to the precipitation of W-ISS and W-ISM carbonates (Figure 3(a)).

Our oxygen isotopic data reveal that interstellar water ices contributed significantly to the total Paris water budget. This is confirmed by the bulk $\mathrm{D} / \mathrm{H}$ ratio of Paris that shows significant $\mathrm{D}$ enrichment (i.e., $\mathrm{D} / \mathrm{H}=(167 \pm 0.2) \times 10^{-6}$; Figure 1$)$ relative to (i) the mean $(\mathrm{D} / \mathrm{H})$ of $\mathrm{CM}$ chondrites $\left(139 \times 10^{-6}\right)$ and (ii) the putative $\mathrm{D} / \mathrm{H}$ of local $\mathrm{CM}$ water (i.e., $\mathrm{D} / \mathrm{H}=$ $(82 \pm 1.5) \times 10^{-6}$; Alexander et al. 2012). Such a result is in line with the asymmetric distribution of bulk $\mathrm{D} / \mathrm{H}$ ratios toward cometary values observed in carbonaceous chondrites, which suggests significant contribution of water ice grains coming from the outer part of the solar system (Robert 2006). In addition, even though the $\mathrm{D} / \mathrm{H}$ ratio of only one other $\mathrm{W}$-ISM carbonate-bearing CM is available (Alexander et al. 2012) (i.e., LON 94091), we note that this CM shows also a significant enrichment in deuterium (Alexander et al. 2012) (i.e., $\mathrm{D} / \mathrm{H}=$ $\left.152 \times 10^{-6}\right)$. Given the initial $\mathrm{D} / \mathrm{H}$ inferred for inner solar system water $\left(\mathrm{D} / \mathrm{H}=(82 \pm 1.5) \times 10^{-6} ; \quad\right.$ (Alexander et al. 2012)) and the recent determination of the $\mathrm{D} / \mathrm{H}$ of the Comet 67P (i.e., $\mathrm{D} / \mathrm{H}=(530 \pm 70) \times 10^{-6}$; Altwegg et al. 2015), the D enrichment observed in LON 94091 and Paris can be explained by a contribution of $15.5 \%$ and $19 \%$ of interstellar water ice grains, supporting our mass balance calculation based on the $\mathrm{O}$-isotopic composition of carbonates. Thus, we propose that the abundance of interstellar water varies among CM chondrites, affecting their isotopic $\mathrm{D} / \mathrm{H}$ and $\mathrm{O}$-isotopic compositions at both the bulk and mineral scales.

The presence of interstellar water ices from the outer part of the solar system in $\mathrm{CM}$ chondrites requires inward radial transport in the protoplanetary disk, which could be achieved either by gas drag (Lunine 2006) or turbulent diffusion (Jacquet $\&$ Robert 2013). An alternative scenario could involve impacts between asteroids formed in the main belt and ice-rich bodies coming from the outer part of the solar system due to planetesimal migration induced by the early core formation of Jupiter and Saturn (Grazier et al. 2014). Interestingly, the latter scenario would have generated collisions at velocities low enough to have allowed fragments to be re-accreted and this could therefore account for the highly brecciated nature of $\mathrm{CM}$ chondrites (Brearley 2006; Briani et al. 2012). In addition, this model predicts that a large fraction of water and volatiles in the main belt originates from the outer solar system, in line with (i) the finding of this study and the recent detection of ammoniated phyllosilicates at the surface of (1) Ceres (De Sanctis et al. 2015) and (ii) disk ionization modeling that suggests that terrestrial oceans should contain 7 to $30 \%-50 \%$ of interstellar ices (Cleeves et al. 2014).

Taken together, these results reveal the presence of interstellar water ices in the accretion zone of carbonaceous chondrites at a level of $8 \%-35 \%$. This is consistent with the contribution of interstellar ices at a level of $9 \%$ in ordinary chondrites determined from the $\mathrm{D} / \mathrm{H}$ ratios of organic matter/ phyllosilicates intergrowths (Piani et al. 2015). As the accretion of carbonaceous chondrites may have predated the accretion of ordinary chondrites (Jacquet et al. 2012), this would suggest that the inward transport of interstellar water ices took place early in the history of the Solar protoplanetary disk. Thus, isotopic compositions of chondrites and hydrodynamical modeling both show that outer disk materials contributed significantly to the delivery of water and volatile elements in the chondrite- and Earth-accretion regions (Cleeves et al. 2014; Marty et al. 2016).

\section{CONCLUSIONS}

The in situ analysis of the oxygen isotopic compositions of Ca-carbonates in the pristine $\mathrm{CM}$ chondrite Paris revealed the presence of two distinct trends in a $\delta^{17} \mathrm{O}-\delta^{18} \mathrm{O}$ diagram. They are respectively characterized by (i) large isotopic variations, with $\Delta^{17} \mathrm{O}<0$ and a slope of 0.65 and (ii) less isotopic variation, with $\Delta^{17} \mathrm{O}>0$ and a steeper slope $>1$. While the former is coherent with an inner solar system origin of water, the latter highlights the presence of interstellar water in Paris. Based on mass balance calculations, we estimate that Paris contains 8 to $35 \%$ of interstellar water. The bulk D/H of Paris present significant $\mathrm{D}$ enrichment $\left(\mathrm{D} / \mathrm{H}=(167 \pm 0.2) \times 10^{-6}\right)$ relative to the mean $\mathrm{D} / \mathrm{H}$ of $\mathrm{CM}$ chondrites $\left((139 \pm 3) \times 10^{-6}\right)$ and the putative $\mathrm{D} / \mathrm{H}$ of local $\mathrm{CM}$ water $\left((82 \pm 1.5) \times 10^{-6}\right)$. This confirmed the presence of interstellar water in the Paris chondrite. Our results are coherent with previous studies that suggest efficient radial mixing of interstellar ices from the outer zone of the Solar protoplanetary disk.

We are grateful to Guillaume Avice for his helpful discussions and to Nordine Bouden for his assistance with oxygen isotopic measurements. We thank Thomas Rigaudier and Christian France-Lanord for the determination of the $\mathrm{D} / \mathrm{H}$ isotopic composition of the Paris chondrite. This work was funded by l'Agence Nationale de la Recherche through grant ANR-14-CE33-0002-01 SAPINS (PI Yves Marrocchi). This is CRPG contribution \#2440 and SAPINS contribution \#07.

\section{REFERENCES}

Alexander, C. M. O., Bowden, R., Fogel, M. L., et al. 2012, Sci, 337, 721 Altwegg, K., Balsiger, H., Bar-Nun, A., et al. 2015, Sci, 347, 1261952

Benedix, G. K., Leshin, L. A., Farquhar, J., \& Jackson, T. 2003, GeCoA, 67, 1577

Bland, P., Jackson, M. D., Coker, R. F., et al. 2009, E\&PSL, 287, 559

Boato, G. 1954, GeCoA, 6, 209

Bradley, J. P., Heinrich, D. H., \& Karl, K. T. 2007, in Interplanetary Dust Particles, Treatise on Geochemistry, ed. H. D. Holland \& K. K. Turekian (Oxford: Pergamon), 689

Brearley, A. J. 2006, in Meteorites and Early Solar System II, ed. D. S. Lauretta \& H. Y. McSween (Tucson, AZ: Univ. Arizona Press), 587 Briani, G., Gounelle, M., Bourot-Denise, M., \& Zolensky, M. E. 2012, M\&PS, 47,880

Clayton, R. N. 2002, Natur, 415, 860

Clayton, R. N., \& Mayeda, T. K. 1999, GeCoA, 63, 2089 
Cleeves, L. I., Bergin, E. A., Alexander, C. M. O. d'., et al. 2014, Sci, 345,1590

De Sanctis, M. C., Ammannito, E., Raponi, A., et al. 2015, Natur, 528, 241

Duprat, J., Dobrica, E., Engrand, C., et al. 2010, Sci, 328, 742

Fujiya, W., Sugiura, N., Marrocchi, Y., et al. 2015, GeCoA, 161, 101

Gaudin, A., Ansan, S., \& Rigaudier, T. 2015, Catena, 133, 97

Geiss, J., \& Gloeckler, G. 2003, in Solar System History from Isotopic Signatures of Volatile Elements, Vol. 16, ed. R. Kallenbach et al. (Dordrecht: Springer Netherlands)

Grazier, K. R., Castillo-Rogez, J. C., \& Sharp, P. W. 2014, Icar, 232, 13

Hewins, R. H., Bourot-Denise, M., Zanda, B., et al. 2014, GeCoA, 124, 190

Horstmann, M., Vollmer, C., Barth, M. I. F., et al. 2014, LPSC, 45, 1761

Jacquet, E., Gounelle, M., \& Fromang, S. 2012, Icar, 220, 162

Jacquet, E., \& Robert, F. 2013, Icar, 223, 722

Kerridge, J. F. 1985, GeCoA, 49, 1707

Kim, S. T., \& O’Neil, J. R. 1997, GeCoA, 61, 3461

Kolodny, Y., Kerridge, J. F., \& Kaplan, I. R. 1980, E\&PSL, 46, 149

Lee, M. R., Lindgren, P., \& Sofe, M. R. 2014, GeCoA, 144, 126

Lee, M. R., Sofe, M. R., Lindgren, P., Starkey, N. A., \& Franchi, I. A. 2013 , GeCoA, 121, 452

Lunine, J. I. 2006, in Meteorites and the Early Solar System II, ed. D. S. Lauretta \& H. Y. McSween, Jr. (Tucson, AZ: Univ. Arizona Press), 309

Lupker, M., France-Lanord, C., Galy, V., et al. 2012, GeCoA, 84, 410

Lyons, J. R., \& Young, E. D. 2005, Natur, 435, 317
Marrocchi, Y., \& Chaussidon, M. 2015, E\&PSL, 430, 308

Marrocchi, Y., Gounelle, M., Blanchard, I., Caste, F., \& Kearsley, A. T. 2014, M\&PS, 49, 1232

Marrocchi, Y., \& Libourel, G. 2013, GeCoA, 119, 117

Marty, B., Avice, G., Sano, Y., et al. 2016, E\&PSL, 441, 91

Nittler, L. R., Davidson, J., Liu, N., Alexander, C. M. O. D., \& Stroud, R. M. 2015, LPSC, 46, 2097

Piani, L., Robert, F., Beyssac, O., et al. 2012, M\&PS, 47, 8

Piani, L., Robert, F., \& Remusat, L. 2015, E\&PSL, 415, 154

Pignatelli, I., Marrocchi, Y., \& Vacher, L. G. 2016, M\&PS, 51, 785

Rivkin, A. S., Howell, E. S., Vilas, F., \& Lebofsky, L. A. 2002, in Asteroids III, ed. W. Bottke et al. (Tucson, AZ: Univ. Arizona Press), 235

Robert, F. 2006, in Meteorites and the Early Solar System II, ed. D. S. Lauretta \& H. Y. McSween, Jr. (Tucson, AZ: Univ. Arizona Press), 341

Robert, F., \& Epstein, S. 1982, GeCoA, 46, 81

Sakamoto, N., Seto, Y., Itoh, S., et al. 2007, Sci, 317, 231

Scott, E. R. D., \& Krot, A. N. 2014, Treatise on Geochemistry, ed. A. M. Davis (Oxford: Elsevier), 65

Tyra, M., Brearley, A., \& Guan, Y. 2016, GeCoA, 175, 195

Tyra, M. A., Farquhar, J., Guan, Y., \& Leshin, L. A. 2012, GeCoA, 77, 383

Yang, J., \& Epstein, S. 1983, GeCoA, 47, 2199

Yurimoto, H., Krot, A. N., Choi, B. G., et al. 2008, Rev. Mineral. Geochem., 68, 141 